Hanna-Maija Huhtala \& Katariina Holma (2019)

Ethics and Education, DOI: 10.1080/17449642.2019.1587684

\title{
Education of moral beings: the distortion of Habermas' empirical sources
}

\begin{abstract}
This article scrutinises one of the mainstream views of how one grows into responsible membership of society; the view based on Jürgen Habermas', Lawrence Kohlberg's and Jean Piaget's theories. Habermas praises Kohlberg's and Piaget's psychological theories and uses them as empirical sources crucial for his theoretical work. We argue that this view should be revised in light of new empirical findings as Habermas' Kohlberg's and Piaget's view is based on a false understanding of the development and functioning of human reason and morality. We do not, however, defend a view that reduces normative questions to empirical facts. In contrast, we agree with Habermas that in an adequate (educational) theory, both philosophical and empirical dimensions have to be taken into account but argue that the empirical research results he has utilized are fallacious in light of current research findings. Finally, we discuss the relevance of our argument for educational theorisation.
\end{abstract}

KEYWORDS Morality; rationality; Habermas; Piaget; Kohlberg

\section{Introduction}

One crucial dimension of an individual's moral agency is her capability of being a responsible member of society at both local and global levels. This article scrutinises one of the mainstream conceptualisations of how one grows into responsible membership, arguing that this view should be revised in light of new empirical understandings of the development of human morality. The mainstream view to which we refer, which still underlies various educational approaches aimed at fostering democratic citizenship, is based on the combined views of Habermas, Piaget and Kohlberg. These three theorists are closely related to each other, as Habermas praises Piaget's and Kohlberg's psychological theories and uses them as empirical sources crucial for his theoretical work (Bookman 2002; Endres 1996; Habermas 1984; Hoechst 2008). Furthermore, contemporary views on moral development continue to draw heavily on Piagetian and Kohlbergian theories (Boom 2011; Çam et al. 2012; Dawson 2002; Oesterdiekhoff 2013; Pritchard 1999; Saran 2007). In our view, the problematic account concerning the close relationship between the developments of morality and reason is shared by all these theorists. In this article, we first demonstrate what we take as a fallacious assumption underlying the theories of Habermas, Piaget, and Kohlberg and then draw on contemporary research in order to demonstrate the problematic nature of Habermasian- PiagetianKohlbergian views. Finally, we discuss the relevance of our argument for educational theorisation. 
The relationship between rationality and morality, as interpreted in the Western philosophical tradition has been criticised from many angles. Feminist philosophy has illustrated how the Western philosophical tradition has associated reason (and morality) with men and emotion with women, indicating that women (being emotional) are closer to nature and, therefore, inferior to men in their rational abilities (Alcoff and Kittay 2007, 2-5; Lloyd 1995). According to criticisms originating from the ethics of care, for its part, Western philosophy has largely ignored the inherently relational and, thus, vulnerable dimensions of human beings, suggesting that instead of reason, care should be the core of morality (e.g. Gilligan 2008; Slote 2007; Noddings 1984). From the angle of environmental ethics, the human-centeredness of Western philosophy distorts morality and undermines the moral value and status of non-human and non-rational beings (Taylor 1989). In the research tradition of phenomenology (e.g. Merleau-Ponty 1962), the reason-emotion dichotomy has been questioned by underlining the role of the body and embodied experience. Lastly, poststructuralism has aimed to deconstruct the entire reason-emotion dichotomy underlying the rational conception of morality by asserting this dichotomy as a historical construct (e.g. Canguilhem 1978; Foucault 1978). While these critiques are versatile and extensive, we believe that our criticism covers an important, yet insufficiently scrutinised, dimension: the role that empirical knowledge has played in one of the mainstream theories of the development of human morality and rationality and how contemporary research findings challenge this empirical knowledge. ${ }^{i}$

In order to avoid potential sources of misunderstanding, we clarify two points. First although we argue that empirical research results should play a role in educational theorising, we do not defend a view in which answers to normative questions of moral philosophy can be reduced to empirical facts. In contrast, we argue that in an adequate educational theory, both normative and descriptive dimensions have to be taken into account (e.g. Holma and Hyytinen 2015). Second, although we aim to point out that the developments of morality and rationality are separate processes, we do not deny the role of reason in developing and revising our moral views. Our approach and argument can thus be outlined as follows: in order to be successful, an adequate educational theory has to take both descriptive (real world) and normative (ideal world) aspects into account. However, in one of the mainstream views in which this was attempted, the descriptive part is based partly on false empirical assumptions. This problematic view, formulated by Habermas, ${ }^{\text {ii }}$ still has an effect on how we think about moral education and, in particular, on many pedagogical approaches and applications. In what follows, we analyse these false assumptions and discuss the kinds of effects the revision of these assumptions, in the light of current empirical knowledge, might have on our understanding of the education of moral beings.

\section{The development of reason and the development of morality - the distortion of Habermas and his empirical sources}

In this section, we examine the way in which Habermas utilises Kohlberg's and Piaget's theorisations. We also demonstrate that Habermas', Kohlberg's and Piaget's theoretical frameworks are ultimately based on the same problematic understanding of rational abilities and moral development. In particular, Habermas' theory of communicative action, which is part of his broader project on discourse ethics, draws on Piaget's and Kohlberg's thinking. Habermas credits the theories of Piaget 
and Kohlberg, specifically for their ability to abide philosophically-orientated theorisations with methodologically-sound empirical research (Habermas 1983, 117; Bookman 2002, 77). Habermas stresses the need for correspondence between philosophical theories and empirical research findings and theories that are further based on these findings. ${ }^{\text {iii }}$ The main insight Habermas draws from Kohlberg's work is the latter's theory of the development of moral consciousness (Habermas 1983, 116-122). From Piaget, Habermas adopts the view of genetic structuralism (Habermas 1976, 169). We shall now focus on these ideas of Kohlberg and Piaget in greater detail.

Habermas is very explicit about the relationship between his discourse ethics and Kohlberg's theory of moral development. He argues that his discourse ethics, particularly in stressing the role of communicative action, rounds out Kohlberg's theory of the development of moral consciousness (Habermas 1983, 118) and that the congruence of the two theories - Kohlberg's theory of moral development and his discourse ethics - serves indirectly as a validation of discourse ethics (Habermas 1983, 116-117). One central characteristic of this view is that one's moral development is tightly connected to one's ability to give reasons for one's moral choices (Habermas 1983, 120; Kohlberg 1981). It seems that in Habermas' view, the highest level of Kohlberg's three stages of moral development - the post-conventional level - is a necessary condition for the realisation of the ideals of discourse ethics. As he states: 'complete reversibility of the perspectives from which participants produce their arguments; universality, understood as the inclusion of all concerned; and the reciprocity of equal recognition of the claims of each participant by all others' (Habermas 1983, 122). The Kohlbergian idea of the highest level, both as somewhat universal and achievable to most human beings, is actually a central building block in Habermas' discourse ethics. This is mainly because, in his view, in order to find solutions to moral problems, we need agents who can follow particular procedural guidelines. Therefore, as we discuss later, if Kohlberg's theory of moral development turned out to be problematic at an empirical level, it would cast doubt on the relevance of discourse ethics as an ideal worth pursuing, for example, through education.

From Piaget, Habermas derives the view of genetic structuralism (Habermas 1976, 169), which he takes as 'a model of the growth of rationality' (Kitchener 1991, 434). Furthermore, Habermas extends Piaget's model for learning to describe the development of worldviews (Habermas 1976, 121, 169). This is to say that for Piaget, learning is understood in terms of structural changes at the levels of learning capacity (Piaget 1971, 15, 77, see also Genovese 2003, 128), and for Habermas, these kinds of structural changes can also be seen in the development of worldviews. In Habermas' view, Piagetian levels should not be understood 'solely as the construction of an external universe but also as the construction of a reference system for the simultaneous demarcation of the objective and social worlds from the subjective world. Cognitive development signifies in general the decentration of an egocentric understanding of the world' (Habermas 1984, 69). Habermas seems not only convinced about Piaget's theory of progressive stages of cognitive development, but he also extends this theory to the universal theory of the development of societies (Habermas 1976, 121). Furthermore, he thinks that Piaget's theory of genetic structuralism builds a kind of empirical bridge to historical materialism. In Habermas' words: 'only the genetic structuralism worked out by Piaget, which investigates the development logic behind the process in which structures are formed, builds a bridge to historical materialism . . . it offers the possibility of bringing different modes of production under abstract developmental-logical viewpoints' (Habermas 1976, 169). 
Deriving from Piagetian and Kohlbergian sources, Habermas locates reason between individuals as existing in the structures of communication. There, the Piagetian view of cognitive development that stresses structures, rather than the contents of knowledge (Piaget 1971, 1, 14-15), ${ }^{\text {iv }}$ is extended to Habermas' view of rationality as procedural: 'rationality has less to do with the possession of knowledge than with how speaking and acting subjects acquire and use knowledge' (Habermas 1984, 8). This idea is central to Habermas' outline of formal guidelines for communication situations as well as the competencies that these situations require from individuals. According to Habermas, these elements combined enable reason to reach its full potentiality: communicative reason, as he names it.

It thus seems to us that there is some confusion between the empirical validity of Habermas' theory and the ideal conditions of communication and communicative reason. Of course, at a philosophical level, there is nothing one can hold against Habermas constructing an ideal theory of communication and communicative reason. However, once he takes theories based on empirical research as dimensions or even 'validations' (Habermas 1983, 117) of his philosophical theory, one has to enquire about the adequacy of these empirical sources. This question is even more poignant in the philosophy of education where one of our aims is to bridge the gap between philosophical ideals and current reality as a way of approaching ideals (e.g. Jaggar 2014, 35; Holma and Huhtala 2014). In our view, Habermas' theory of communicative reason constructs an ideal, which, contrary to Habermas' own assertions, corresponds weakly to the actual (moral) reasoning processes of individuals. Habermas' model places great trust in establishing transparent worldviews and eventually transmitting them through the medium of communication. In the next section, we demonstrate in greater detail the problematic nature of the basic presumptions underlying these views in light of contemporary empirical evidence of human reason and morality.

\section{The connection between reason and morality - how contemporary psychological research findings challenge the empirical views adopted by Habermas}

Here, we introduce some contemporary empirical research findings and the theories derived from these findings, which challenge the legacies of Piaget and Kohlberg. As mentioned earlier, we agree with Habermas that in constructing theories of the ideal states of human rationality, morality or the just society, one must be informed by empirical research on the conditions of development and advancements in human reason and morality. Furthermore, we also agree with him regarding the importance of building a theory about the ideal procedures of a just society. However, in order to build an adequate theory about the ideal procedures, one should not rely on fallacious empirical sources. Moreover, as we will discuss in the concluding section, in the field of education, an adequate understanding of the empirical conditions of reason and morality is even more important for adequately pursuing the adopted ideals through education.

The main problems in the theories utilised by Habermas are, first, the idea of stages of development, both in moral development and the development of cognitive abilities and, second, the idea of the close relationship between one's moral stage and an ability to give reasons for one's moral choices. In light of contemporary empirical research from moral, social and neuropsychology, the processes 
through which humans develop either as rational or moral beings turned out to be much more complicated than Piaget or Kohlberg supposed. The main results contradicting Kohlberg and Piaget (as well as Habermas to the extent that he relies on their theories) are 1) that we humans think of ourselves as forming rational beliefs and making rational decisions also in cases we are not doing so: we are not aware of the fundamental role of corporeality and emotions in our thinking and decision making and 2) that we are not aware of either the epistemic force or the limitations of information brought on by our emotions. In some cases, emotions can provide us with adequate (although fallible) information (e.g. Scheffler 1991, 3-17), whereas in others, we must consider them as biased.

Contrary to the Kohlbergian view, we humans approach situations in which we formulate moral beliefs or make moral choices primarily by emotions and intuitions (Haidt 2012, 52-59) and only secondarily through our reasoning processes (Hauser 2006). The primacy of emotion and intuition means that before we reach cognitive awareness regarding our moral stance about certain moral issues, we have already settled our position intuitively and emotionally (Bechara et al. 1994, 1997; Cohen 2005; Damasio 1994, 1996; Greene and Baron 2001; Greene et al. 2008; Hogarth 2001; Kahneman 2003; Kahneman and Frederick 2002; Kahneman and Sunstein 2005; Koenings et al. 2007; Moll et al. 2002; Olatunji, Puncochar, and Kramer 2017; Qiao-Tasserit et al. 2017; Rudert et al. 2017; Slovic et al. 2004). This is to say that while individuals can be efficient at giving reasons for their moral judgements and conducts, these reasons are often ad hoc arguments fabricated to support the original moral view, which is significantly defined by our moral emotions and intuitions (Kahneman and Sunstein 2005). These kind of psychological mechanisms are in progress even before we submit our views for genuine critical investigation or self-reflection. ${ }^{\mathrm{v}}$ Therefore, decision-making and moral-reasoning processes are inbuilt such that individuals are oftentimes unconscious of them. Thus, the starting point for (most) moral deliberations is not the contemplation on moral pros and cons but, instead, developing a narrative that corresponds to our intuitive and emotional moral stance.

In addition, contrary to the view that emotions should be decoupled from adequate moral deliberations, it seems that, in some cases, emotions play an important epistemic function in our acquirement of moral knowledge (e.g. Prinz 2009). According to both conclusions advanced by Greene and Haidt from various empirical research, moral emotions are designed to enable cooperation between the individual and his or her tribe members; they gird us physically to act accordingly (Greene 2013, 258-262, 293; Haidt 2012, 219-366, 270-274). In the views of Greene and Haidt, morality evolved as the human brain's solution to the challenge of cooperation, with 'moral brains' being biologically programmed to unify individuals into groups (Greene 2013, 59). This is to say that on one hand, we are driven by individual self-interest; on the other, we are profoundly programmed for cooperation. There, our moral emotions help us in finding cooperative solutions instead of selfish ones.

However, cooperation does not mean collaboration with any- and everyone; rather, it appears to be selective, in-group cooperation, originally designed for defeating competing groups (Haidt 2012, 224, 235-237, 253). In sharing our social lives with others (by necessity), we need to constantly find ways (consciously and unconsciously) to put others and ourselves in a positive light: cooperation is easier if we like those who we have to get along with. It follows that attending to injustices and the suffering that takes place in the distance then requires a more deliberative response in the absence of automatic 
emotional commitment (Greene 2013, 258-262). Hence, the human capacity to care for others is (psychologically) limited. This means that we are more tuned to the well-being of those who are close to us (emotionally or physically) than that of people who are deemed strange. Injustice and suffering encountered by members of our family or community evoke automatically strong emotional reactions in us; the misery of people who we have never met is not equally important to us. This is to say that our moral emotions are not useless as our source of information, and neither should they always be suppressed as inadequate sources. ${ }^{\mathrm{vi}}$ However, they are also highly context-dependent.

It seems, however, that a potential cure for this context dependence of moral brains comes from a kind of dual-process machinery in our brain. According to Greene $(2013,133)$, our moral brains are designed for functioning either in automatic settings or in manual mode, the latter being flexible and the former efficient (see also Kahneman 2000; Kahneman and Sunstein 2005; Greene et al. 2008). It is possible to switch between the two modes, but they cannot be used simultaneously. The automatic mode takes place in regions that are crucial for emotions, such as the ventromedial prefrontal cortex (VMPFC); deliberative reasoning (manual mode), for its part, is brain activity that mainly occurs at the dorsolateral prefrontal cortex (DLPFC) (Greene 2013, 136-137). In regard to the former, emotions are wired for enabling the automatic efficient mode of reasoning: emotions do the (fast) thinking and produce fitting behaviour (Greene 2013, 136). This mode is shaped by our genes, cultural learning and personal experience, and as mentioned above, it is fast, intuitive and connected to emotions (hence: emotions have epistemic value). The two operating modes enable us, e.g. to weigh the value of postponing gratification instead of pursuing immediate gratification (at the same time, we may want two contradictory things, both granting and denying something from ourselves). Deliberative moral reasoning (manual mode) and theorisations of moral philosophy often overwrite the automatic mode. It is where our moral reasoning starts to revise our original 'instincts'. For example, if one belongs to the cultural circle of modern Western societies, one is likely to overwrite the negative emotional reaction of disgust or anger - related, for example, to sexual orientations that differ from one's own - by employing the moral code which sees an act as morally right if no harm is caused to anyone (Haidt 2012). ${ }^{\text {vii }}$

To sum up, the Habermasian idea of rational reflection of our moral beliefs and actions is much more difficult to reach than Kohlbergian and Piagetian conceptualisations suggest. We certainly need this kind of reflection in our plural and multicultural societies where, based on the evolutionary need for cooperation, we have to reach beyond our moral 'instincts'. viii However, it seems that the most adequate starting point for such theorising is not the ideal of the self-constructing individual who relies on the abstract ideals of formal principles of justice which 'we want all people to adopt always in all situations' (Kohlberg 1981, 39). This is simply because if we construct ideals that are based on entirely fallacious conceptions of what we humans are and what we can become, we may lose the opportunity to really develop theories for a better society. In Scheffler's (1991) critique of the Kohlbergian view of moral development, he notes in this regard: '[C]rucial as proper reasoning is to moral life, and therefore moral education, it has its natural limits. Indeed, nothing can substitute for such reasoning, yet it cannot stand alone' (98). 


\section{Education of moral beings in light of contemporary research findings}

Philosophical theories based on ideals that have no connection with empirical reality can be problematic if these philosopher-constructed ideals are entirely unattainable to human beings and society at large. When we bring such theories to the field of education and begin to strive for the realisation of these ideals by educational means, the ensuing problems may be fatal. For example, according to Holma (2012), the common trust in teaching cognitive and rational abilities (so-called critical thinking skills, for example) as crucial to democratic citizenship may also work towards an unintended, contradictory end: these abilities can be used self-deceptively to bolster rationalisations (e.g. Audi 1997, 131-156; Nussbaum 1990, 261-285) and, thus, they may 'assist one in constructing an illusion of one's own certainty and infallibility' (Holma 2012, 405).

Likewise, the Habermasian ideal of communicative reason, when backed by Kohlbergian and Piagetian theories and put into practice in the field of education, can be a harmful ideal too. To understand more adequately the empirical conditions behind human reason and morality, the most important contemporary findings we need to consider are that 1) corporeal emotions connect to and shape our moral beliefs, and that 2) critical thinking skills (usually taken as crucial for democratic citizenship) are, more often than not, unconsciously deployed to safeguard views that individuals already endorse despite the epistemic weight of the counterarguments. It seems to us that these research findings actually point (at least partly) in the same direction as many earlier criticisms of the role of reason in philosophy and the philosophy of education, which were offered, among others, by feminist philosophers, environmental philosophers and defenders of the ethics of care. However, rather than replacing the ideal of reason with other ideals, we want to engage with the empirical conditions and limitations in reaching this ideal and the related revision to educational theories in light of these conditions.

The fact that embodied emotions guide our reasoning processes in ways that we are not aware of should be taken more seriously in education. The experience of the rightfulness of one's own position might often be so compelling that reason is employed to defend this position rather than being geared towards critical selfreflection. Thus, individuals themselves do not fully grasp the primary motivation behind their reasoning and argumentation processes. Of course, a consequence of this is that education should pay more attention to recognising the emotional reactions behind our conclusions, of which we ourselves believe that they are based on the premises of objectivity and rationality.

However, it is not only that we should identify and recognise our emotions. This would not actually differ very much from one of the mainstream views of Western philosophy, which posits that we have to keep our emotions from disturbing our rational procedures. In addition, it seems that in some cases, emotions can serve as an adequate source of information for our moral choices. In epistemological terms, emotions must be considered as one potential but fallible source of information in our moral considerations. In education, this idea would require a much more nuanced understanding of the role of emotions in moral education and development. This would mean, for example, teaching children how to listen and read (not to simply either follow or supress) their moral emotions and gut feelings. 
Our corporeal reactions and emotions bear important moral cues, which should not be suppressed or ignored (Huhtala 2016, 699-700). Education that neglects the importance of the entwined relation of reason and emotion might promote the upbringing of skilful rationalisers who are able to provide excellent arguments and reasons even for their immoral decisions. It is not only necessary to identify the central role of emotions but also to investigate and support their epistemic force.

The overall aim of this article was to advance a more accurate understanding about human morality and reason deriving from recent findings from moral and social psychology. The education of moral beings, as viewed by Habermasian-Piagetian-Kohlbergian theories, emphasises rational skills that are detached from embodied emotions, whereas contemporary research emphasises the deeply intertwined nature of reason and emotion in our thinking, reasoning, and morality. We see it as crucial to bring contemporary empirical findings into dialogue with the philosophical ideals in order to rethink the theorizations of moral education.

\section{Notes}

${ }^{\mathrm{i}}$ In a recently published article Huhtala (2017) discusses naturalistic moral philosophy and the insufficiency of reason as the core of morality from the viewpoint of Theodor W. Adorno's philosophy.

ii In the 1970s and 1980s, Habermas' project of discourse ethics was characterised by a strong interest in connecting philosophical theories to empirical research findings. In particular, the works Communication and the Evolution of Society (1976) and Moral Consciousness and Communicative Action (1983) drew heavily on Piaget's and Kohlberg's theories. Habermas then moved on, and his philosophy focused on different themes, e.g. 'privatization' (1985-2000) and, in the late 1990s, 'publicization' (Portier 2011, 426).

iii There are two different tendencies in Habermasian thought, as he emphasises both the importance of the close connection between empirical sciences and philosophy (Habermas 1983, 116-119) and emancipation as the goal of his idea of reconstructive sciences (Alford 1985, 324). The space constraints of this article do not allow for a discussion of whether these tendencies are contradictory. We focus on Habermas' way of using empirical knowledge as part of his theory building.

iv One problematic dimension of Piaget's theories is his belief that we can discover the general conditions of knowledge construction in science by observing children (Piaget 1971, 13-14). Furthermore, he examined children's cognitive development specifically by observing his own (three) children (Saran 2007, 191), deriving universal conclusions from these observations.

See also Epstein 1994; Kahneman 1994; Moll et al. 2002.

${ }^{\mathrm{vi}}$ In the field of moral philosophy, Kurth (2018) has introduced an empirically informed philosophical account of emotions as bio-cognitive models, which can directly steer the cognitive processes of knowledge inquiry. Kurth focuses particularly on the emotion of anxiety as a forward-looking (future-orientated) emotion that may enhance an individual's performance, help her identify potential threats and (inner moral or social) conflicts, and by evoking alertness, anxiety may even smoothen social interactions (1-6). 
vii Haidt used the notion of 'WEIRD'to describe prevailing moral accounts in Western societies. The acronym WEIRD refers to the sizeable minority of white, educated, industrialised, rich and democratic citizens who share the same liberal moral foundation. According to Haidt, and perhaps going against common judgement, the moral domain of WEIRD cultures is remarkably narrow, mainly stressing the dimension of moral autonomy $(2012,129)$.

viii Although his starting point is an evolutionary understanding of human development and behaviour, Greene interestingly comes close to Kantian moral philosophy. He suggests that by acknowledging that all human beings have the common desire for happiness and by committing ourselves to the principle of the Golden Rule (met in most, if not all, philosophical and religious worldviews) and its idea of impartiality, we avoid the backdrop of relativism (Greene 2013, 340). Greene's moral theory seems to be suggestive of universalism in the sense that he detects common features shared with all humans and the universal moral principle of the Golden Rule as the basis of moral theory in heeding moral pluralism. Greene argues that without acknowledging both, the shared desire for happiness and treating others as you wish to be treated - the core message of the Golden rule - we have no standard for assessing different moral systems, which makes us subject to moral compromises against our moral intuitions and reasoning. In this way, contemporary findings also emphasise the role of moral reasoning. According to Greene, the aim to maximise global happiness is a metamoral ideal that places moral reasoning prior to our moral intuitions (Greene 2013, 345-346).

\section{Acknowledgements}

This research was supported financially by the Eudaimonia Institute of the University of Oulu and is part of the project Citizenship in Change: Constructing a Novel Theoretical Framework for Education. This research was also supported financially by the Kone Foundation. We are thankful for the support.

\section{References}

Alford, C. F. 1985. "Is Jürgen Habermas's Reconstructive Science Really Science?” Theory \& Society 14 (3): 321-340. doi:10.1007/BF00161281.

Allcoff, L. M., and E. F. Kittay, ed. 2007. The Blackwell Guide to Feminist Philosophy. Malden: Blackwell Publishing.

Audi, R. 1997. Moral Knowledge and Ethical Character. Oxford: Oxford University Press.

Bechara, A., A. R. Damasio, H. Damasio, and S. W. Anderson. 1994. "Insensitivity to Future Consequences following Damage to Human Prefrontal Cortex." Cognition 50 (1-3): 7-15. doi:10.1016/0010-0277(94)90018-3.

Bechara, A., H. Damasio, D. Tranel, and A. R. Damasio. 1997. "Deciding Advantageously before Knowing the Advantageous Strategy.” Science 275: 1293-1295. doi:10.1126/ science.275.5304.1293.

Bookman, M. 2002. "Forming Competence: Habermas on Reconstructing Worlds and Context-Transcendent Reason." In Habermas and Pragmatism, edited by M. Aboulafia, M. Bookman, and A. Kemp, 65-79. London: Routledge.

Boom, J. 2011. "Egocentrism in Moral Development: Gibbs, Piaget, Kohlberg." New Ideas in Psychology 29 (3): 355-363. doi:10.1016/j.newideapsych.2010.03.007.

Çam, Z., D. Çavdar, S. Seydoogullari, and F. Çok. 2012. "Classical and Contemporary Approaches for Moral Development.” Educational Sciences: Theory \& Practice 12: 1222-1225. 
Canguilhem, G. 1978. On the Normal and the Pathological: Studies in the History of Modern Science 3. Dordrecht: D. Reidel Publishing Company.

Cohen, J. D. 2005. "The Vulcanization of the Human Brain: A Neural Perspective on Interactions between Cognition and Emotion.” Journal of Economic Perspectives 19 (4): 3-24. doi:10.1257/089533005775196750.

Damasio, A. R. 1994. Descartes' Error: Emotion, Reason, and the Human Brain. New York (N.Y.): Grosset/Putnam Book.

Damasio, A. R. 1996. "The Somatic Marker Hypothesis and the Possible Functions of the Prefrontal Cortex.” Philosophical Transactions: Biological Sciences 351 (1346): 1413-1420. doi:10.1098/rstb.1996.0125.

Dawson, T. L. 2002. "New Tools, New Insights: Kohlberg's Moral Judgement Stages Revisited.” International Journal of Behavioral Development 26 (2): 154-166. doi:10.1080/ 01650250042000645.

Endres, B. 1996. "Habermas and Critical Thinking.” In Philosophy of Education Yearbook, edited by F. Margonis, 168-177. Urbana, IL: Philosophy of Education Society.

Epstein, S. 1994. "Integration of the Cognitive and Psychodynamic Unconscious." American Psychologist 49: 709-724. doi:10.1037/0003-066X.49.8.709.

Foucault, M. 1978. "Introduction." In On the Normal and the Pathological: Studies in the History of Modern Science 3, edited by G. Canguilhem, ix-xx. Dordrect: D. Reidel Publishing Company.

Genovese, J. 2003. "Piaget, Pedagogy, and Evolutionary Psychology.” Evolutionary Psychology 1: 127-137. doi:10.1177/147470490300100109.

Gilligan, C. 2008. Moral Orientation and Moral Development. The Feminist Philosophy Reader, edited by A. Bailey and C. J. Cuomo. Boston: McGraw-Hill.

Greene, J. 2013. Moral Tribes: Emotion, Reason, and the Gap between Us and Them. New York: Penguin Press.

Greene, J., and J. Baron. 2001. "Intuitions about Declining Marginal Utility.” Journal of Behavioral Decision Making 14: 243-255. doi:10.1002/(ISSN)1099-0771.

Greene, J., S. Morelli, K. Lowenberg, L. Nystrom, and J. Cohen. 2008. “Cognitive Load Selectively Interferes with Utilitarian Moral Judgment.” Cognition 107 (3): 1144-1154. doi:10.1016/j.cognition.2007.11.004.

Habermas, J. 1976. Communication and the Evolution of Society. Translated by T. McCarthy. Boston: Beacon Press.

Habermas, J. 1983. Moral Consciousness and Communicative Action. Cambridge: MIT Press.

Habermas, J. 1984. The Theory of Communicative Action, Volume 1, Reason and the Rationalization of Society. Translated by T. McCarthy. Boston: Beacon Press.

Haidt, J. 2012. The Righteous Minds: Why Good People are Divided by Politics and Religion. New York: Vintage Books.

Hauser, M. 2006. Moral Minds. How Nature Designed Our Universal Sense of Right and Wrong. London: Abacus.

Hoechst, E. H. 2008. Spaces of Freedom: Political Theory and Interpersonal Psychology. Georgetown: Georgetown University.

Hogarth, R. M. 2001. Educating Intuition. Chicago: University of Chicago Press.

Holma, K. 2012. "Fallibilist Pluralism and Education for Shared Citizenship." Educational 
Theory 62 (4): 397-409. doi:10.1111/edth.2012.62.issue-4.

Holma, K., and H.-M. Huhtala. 2014. “Non-Idealizing the Theory of Autonomy: Theodor Adorno's

Psychological and Political Critique of Immanuel Kant." In Philosophy of Education

Yearbook, edited by M. Moses, 373-381. Urbana, IL: Philosophy of Education Society.

Holma, K., and H. Hyytinen. 2015. "The Philosophy of Personal Epistemology." Theory and Research in Education 13 (3): 334-350. doi:10.1177/1477878515606608.

Huhtala, H.-M. 2016. "Finding Educational Insights in Psychoanalytic Theory with Marcuse and Adorno.” Journal of Philosophy of Education 50 (4): 689-704. doi:10.1111/14679752.12194.

Huhtala, H.-M. 2017. "Morality, Culture, and the Educational Stigmata of Capitalism." SATS Northern European Journal of Philosophy 19 (2): 111-138.

Jaggar, A. 2014. "Designing Realistic Educational Utopias Using (Mainly) Non-Ideal Theory." In Philosophy of Education Yearbook, edited by M. Moses, 25-36. Urbana, IL: Philosophy of Education Society.

Kahneman, D. 1994. "New Challenges to the Rationality Assumption.” Journal of Institutional and Theoretical Economics 150 (1): 18-36.

Kahneman, D. 2000. “A Psychological Point of View: Violations of Rational Rules as A Diagnostic of Mental Processes (Commentary on Stanovich and West)." Behavioral and Brain Sciences 23 (5): 681-683.

Kahneman, D., and S. Frederick. 2002. "Representativeness Revisited: Attribute Substitution in Intuitive Judgment." In Heuristics and Biases, edited by T. Gilovich, D. Griffin, and D. Kahneman, 49-81. New York: Cambridge University Press.

Kahneman, D. 2003. "Maps of Bounded Rationality: Psychology for Behavioral Economics."

The American Economic Review 93 (5): 1449-1475. doi:10.1257/000282803322655392.

Kahneman, D., and C. R. Sunstein. 2005. "Cognitive Psychology of Moral Intuitions.” In Neurobiology of Human Values. Research and Perspectives in Neurosciences, edited by J. P. Changeux, A. R. Damasio, W. Singer, and Y. Christen, 91-106. Heidelberg: Springer. Kitchener, R. F. 1991. "Jean Piaget: The Unknown Sociologist?.” The British Journal of Sociology 42 (3): 421-442. doi:10.2307/591188.

Koenings, M., L. Young, R. Adolphs, D. Tranel, F. Cushman, M. Hauser, and A. Damasio. 2007. "Damage to the Prefrontal Cortex Increases Utilitarian Moral Judgements." Nature 446 (7138): 908-911.doi:10.1038/nature05631.

Kohlberg, L. 1981. The Philosophy of Moral Development: Moral Stages and the Idea of Justice. Vol. 1. San Francisco: Harper \& Row.

Kurth, C. 2018. The Anxious Mind: An Investigation into the Varieties and Virtues of Anxiety. Cambridge, MA: MIT Press.

Lloyd, G. 1995. The Man of Reason. "Male" and "Female" in Western Philosophy. London: Routledge.

Merleau-Ponty, M. 1962. Phenomenology of Perception. Translated by C. Smith. London: Routledge and Kegan Paul.

Moll, J., R. de Oliveira-Souza, P. Eslinger, I. Bramati, J. Mourão-Miranda, P. Andreiuolo, and L. Pessoa. 2002. "The Neural Correlates of Moral Sensitivity: A Functional Magnetic Resonance Imaging Investigation of Basic and Moral Emotions.” Journal of Neuroscience 22 (7): 2730-2736. doi:20026214. 
Noddings, N. 1984. Caring: A Feminine Approach to Ethics and Moral Education. Berkeley: University of California Press.

Nussbaum, M. C. 1990. Love's Knowledge: Essays on Philosophy and Literature. Oxford: University Press.

Oesterdiekhoff, G. W. 2013. "Relevance of Piagetian Cross-Cultural Psychology to the Humanities and Social Sciences.” American Journal of Psychology 126 (4): 477-492. doi:10.5406/amerjpsyc.126.4.0477.

Olatunji, B. O., B. D. Puncochar, and L. Kramer. 2017. "Sex Matters: Examination of Disgust and Morality Judgments of Transgressions Committed by Homosexuals and Heterosexuals." Personality and Individual Differences 104 (1): 297-302. doi:10.1016/j.paid.2016.08.028.

Piaget, J. 1971. Genetic Epistemology. New York: W. W. Norton \& Company.

Portier, P. 2011. "Religion and Democracy in the Thought of Jürgen Habermas." Culture and Society 48 (5): 426-432.

Prinz, J. 2009. “The Moral Emotions.” In The Oxford Handbook of Philosophy of Emotion, edited by P. Goldie, 519-538. Oxford: Oxford University Press.

Pritchard, M. S. 1999. "Kohlbergian Contributions to Educational Programs for the Moral Development of Professionals." Educational Psychology Review 11 (4): 395-409. doi:10.1023/A:1022013501159.

Qiao-Tasserit, E., M. Garcia Quesada, L. Antico, D. Bavelier, P. Vuilleumier, and S. Pichon. 2017. "Transient Emotional Events and Individual Affective Traits Affect Emotion Recognition in a Perceptual Decision-Making Task." PLoS ONE 12 (2): 1-16. https://doiorg.ezproxy.uef.fi:2443/10.1371/journal.pone.0171375.

Rudert, S. C., L. Reutner, R. Greifeneder, and M. Walker. 2017. "Faced with Exclusion: Perceived Facial Warmth and Competence Influence Moral Judgments of Social Exclusion.” Journal of Experimental Social Psychology 68 (1): 101-112. doi:10.1016/j.jesp.2016.06.005.

Saran, R. 2007. “Jean Piaget.” In The Praeger Handbook of Education and Psychology, edited by J. L. Kincheloe and R. A. Horn, 190-196. Westport: Praeger.

Scheffler, I. 1991. In Praise of the Cognitive Emotions and Other Essays in the Philosophy of Education. New York: Routledge.

Slote, M. 2007. The Ethics of Care and Empathy. London: Routledge.

Slovic, P., M. L. Finucane, E. Peters, and D. G. MacGregor. 2004. "Risk as Analysis and Risk as Feelings: Some Thoughts about Affect, Reason, Risk, and Rationality.” Risk Analysis 24 (2): 311-322. doi:10.1111/j.0272-4332.2004.00433.x.

Taylor, P. 1989. Respect for Nature: A Theory of Environmental Ethics. Princeton: Princeton University Press. 